\title{
Study of prescription of injectable drugs and intravenous fluids to inpatients in a teaching hospital in Western Nepal
}

\author{
Sudesh Gyawali*, P Ravi Shankar, Archana Saha, Lalit Mohan
}

\begin{abstract}
Unnecessary, excessive and poor injection practices in the South East Asia region (including Nepal) have been observed previously. The authors aim to study prescription of injectable drugs to inpatients in a teaching hospital in Western Nepal. Prescription of injectable drugs (IDs) and intravenous fluids (IVFs) to inpatients discharged from the wards of the Manipal Teaching Hospital during 1st January to 30th June 2006 was studied. The mean number of drugs, IDs and IVFs administered, median cost of drugs and of IDs/IVFs per prescription calculated. Comparison of ID/IVF use in the four major hospital departments (Medicine, Obstetrics and Gynecology, Pediatrics and Surgery) was done. The administration of IDs/IVFs and injectable antimicrobials were measured in Defined Daily Dose (DDD)/100 bed-days and of Intravenous fluid in Liters (L)/100 bed-days.Of the 1131 patients discharged, $938(82.94 \%)$ patients received one or more IDs/IVFs. The mean number of drugs, IDs and IVFs prescribed were 8.75, 4.72 and 1.42. Median cost of drugs and IDs/IVFs per prescription were 8.26US\$ and 5.12US\$ respectively. IDs/IVFs accounted for $81.37 \%$ of total drug cost. The most commonly used ID, injectable antimicrobial and IVF were Diclofenac (19.3 DDD/100 bed-days), Metronidazole (7.68 DDD/100 bed-days) and Dextrose normal saline (8.56 L/100 bed-days), respectively. The total IVF consumption was $24.25 \mathrm{~L} / 100$ bed-days. Significant differences between departments were observed $(\mathbf{p}<\mathbf{0 . 0 5})$. In conclusion, the use of IDs/IVFs was higher compared to other studies. Interventions to improve IDs/IVFs prescribing practices may be required.
\end{abstract}

KEYWORDS: defined daily dose, drug utilization, injectable drugs, inpatients, Nepal, rational use of medicines.

\section{INTRODUCTION}

Drug utilization research is defined as research on "the marketing, distribution, prescription and use of drugs in a society, with special emphasis on the resulting medical, social and economic consequences" and has the principal aim of facilitating the rational use of drugs (1). In developing and transitional countries (including Nepal), some 16 thousand million injections are administered each year - a rate of 3.4 injections per person per year (2). The majority of injections are unnecessary (3). Reuse of injection equipment in the absence of sterilization was highest (75\%) in the South

*To whom correspondence should be addressed

Dr. P. Ravi Shankar

Department of Pharmacology

KIST Medical College

Imadol, Lalitpur, Nepal

E-mail:ravi.dr.shankar@gmail.com
East Asia Region (consisting of nine countries including Nepal) of the World Health Organization (WHO) (2). The combination of injection overuse and unsafe practices creates a major route of transmission for Human Immunodeficiency Virus (HIV), Hepatitis and other blood borne pathogenic infections (2).

In order to compare drug utilization among different countries and even among health institutions within a country, the ATC and DDD concepts were introduced (4). The Anatomical Therapeutic Chemical (ATC) classification system represents a common language for describing the drug assortment. The DDD is defined as the assumed average maintenance dose per day for a drug used for its main indication in adults $(4,5)$. It provides a fixed unit of measurement independent of price and formulation.

A study in the Intensive Care Unit (ICU) from a teaching hospital in Western Nepal showed that 52.8\% 
of drugs were administered by the parenteral route, and more interestingly $74 \%$ of patients were given an intravenous fluid (IVF) during the period of their ICU stay (6). A prospective, cross-sectional study of a tertiary care teaching hospital in Eastern Nepal reported that $77.7 \%$ of the in-patients were prescribed injectable drugs which constituted $40.4 \%$ of the total number of drugs (7). These studies were either confined to a particular department or concentrated on a particular group of drugs.

In view of the high prevalence of use of injectable drugs (IDs) and intravenous fluids (IVFs), there is an urgent need to study their utilization. These data are scant in Nepalese in-patient populations. Knowledge on how IDs/IVFs are being prescribed and used will be of immense help in initiating a discussion on their rational use and suggesting measures to improve prescribing.

The present study was carried out to obtain baseline data on prescription of IDs and IVFs to the inpatients. The objectives of the study were to:

1) Obtain relevant demographic information of inpatients of Manipal Teaching Hospital (MTH) prescribed IDs/IVFs during the study period.

2) Obtain information on the patterns of prescription of IDs/IVFs

3) Calculate DDD/100 bed-days of the ten most commonly used IDs and injectable antibiotics.

4) Measure IVF utilization in liters/100 bed-days.

5) Calculate the proportion of the total drug cost constituted by IDs/IVFs and

6) Analyze and compare the utilization of IDs/IVFs between the MTH's four major departments (Medicine, Obstetrics and Gynecology (OBG), Pediatrics and Surgery).

\section{MATERIALS AND METHODS:}

The study was carried out over a six-month period (1st January to 30th June 2006) at MTH, a 700 bedded tertiary care hospital, affiliated with the Manipal College of Medical Sciences (MCOMS) in Pokhara, Nepal. The middle ten days of each English month was selected to minimize the influence of income on hospital visits. The period covered five days before getting salary and five days after getting salary, since most of the Nepalese people get their salary according to the Nepalese month which start around the middle of the English month. To make things clearer, the Nepalese month of Magh 2065 started on January 14th and will end on February 11th 2009.

Records of patients discharged from the various wards of MTH during the study period were obtained from the medical records department (MRD) and analyzed. Inpatients discharged after observation in the
Emergency department and from the Ophthalmology ward were excluded. Patients admitted for diagnostic procedures such as endoscopy, hemodialysis etc. and discharged after the procedure was also excluded.

Age, Sex, Address, Hospital (patient) number, Department of Admission, Date of Admission and Date of Discharge of the patient were recorded. For calculating the length of stay, the day of admission was included, while that of discharge was excluded. The diagnosis written in the discharge summary was noted. The name, dose, frequency, duration and route of administration of drugs prescribed during hospital stay were recorded.

The patients were divided into four age groups (0-1, $1-15,15-60$ and $>60$ years). Analysis of ID/IVF use in the four major departments was also done separately. The department of Medicine runs the Medicine Outpatient department, Medicine wards, the semi-ICU and the ICU of the hospital. The mean number of drugs, IDs and IVFs administered and their average cost were calculated. The proportion of total drug cost and of total drugs (both injectable and non injectable drugs prescribed to these patients) constituted by IDs/IVFs were calculated. The cost was calculated by using Health Information System (HIS), (developed by the Manipal Corporate office in Bangalore, India) a computer software program used by the hospital pharmacy of MTH. The cost refers only to the cost of drugs and the cost of administration and related fees was not taken into consideration. The cost was calculated in both Nepalese rupees and US dollars (one US dollar $(\mathrm{US} \$)=78.5$ Nepalese rupees $(\mathrm{NRs})$ on $22 \mathrm{nd}$ January 2009). The cost was recalculated to give the latest conversion figures relative to the US dollar.

The drugs were classified according to the ATC system and utilization of IDs was measured in DDD/100 bed-days and of IVFs in L/100 bed-days. Injectable drugs (IDs) refer to drugs which were administered by injection to the patients of the study. Drugs injected into a peripheral intravenous line were also considered as IDs.

The DDD/100 bed-days of the ten most commonly used IDs were calculated using the following formula (4):

$\mathrm{DDD} / 100$ bed-days $=$ (Drug consumption in the study period $(\mathrm{mg}) \times 100) /($ Assigned DDD $(\mathrm{mg}) \times$ Period of study $\times$ Bed strength $\times$ Average occupancy)

The time period of study was sixty days. There were 583 beds in the wards included in the study and the average occupancy index was calculated to be 0.299 .

Intravenous fluid (IVF) utilization was calculated using the following formula: 
(Liters $/ 100$ bed-days $)=($ Consumption of the particular IVF during the study period $(\mathrm{L}) \times 100) /($ Period of study $\times$ Bed strength $\times$ Average occupancy)

For statistical analysis Statistical Package for Social Sciences (SPSS) version 10.0 for windows (SPSS Inc., Chicago, Illinois, United States) was used. One way ANOVA was applied to compare means of various parameters of the four major departments and when significant $(\mathrm{p}<0.001)$ differences were noted, Post hoc Scheff test was applied.

A pilot study of five days duration (11th to 15th December 2005) involving 106 patients was carried out in MTH. The result of the pilot study was not included in the final analysis and was broadly similar to those reported here. The instruments used in the study were standard ones used in previous drug utilization studies.

\section{RESULTS}

During the study period, 1131 patients were discharged, of which 938 (82.94\%) received one or more injection/s during their hospital stay. Percentage of females receiving injections was slightly higher [481 (51.28\% of the total 938 patients receiving injections)] than males. Seventy-six patients were infants (0-1 year), 131 were children (1-15 years), 521 were adults (15-60 years) and 210 were elderly (>60years).

Five hundred and ninety-seven $(63 \%)$ patients were from Kaski district in which MTH is located. A total of 8203 drugs were prescribed with the mean number being 8.75 . IDs/IVFs accounted for $52.8 \%$ of the total drugs. Mean number of IDs/IVFs was 4.72. A single ID/IVF was administered to 168 (17.91\% of total 938$)$ patients, while $145(15.46 \%)$ received two such drugs. Three or more IDs/IVFs were administered to 625 $(66.63 \%)$ patients.

The most common conditions for which an ID was prescribed were hypertension (10.77\%), chronic obstructive pulmonary disease (COPD) (7.78\%), acute gastroenteritis (6.29\%) and ischemic heart disease $(6.08 \%)$.

Of the 938 patients, who received IDs/IVFs, 535 (57.04\%) received parenteral anti-microbial therapy. A single injectable anti-microbial (IAM) was given to 252 (47.1\%) patients, while $161(30.09 \%)$ received two IAMs. Tables 1 and 2 shows the ATC codes and DDD/100 bed-days of the ten most commonly administered IDs and IAMs in MTH respectively.

A total of 1328 IVFs were administered. IVFs were administered to $682(72.71 \%)$ of the 938 patients. Median number of IVF prescribed was one. The total IVF consumption was $24.25 \mathrm{~L} / 100$ bed-days. Table 3 shows the consumption of the most commonly prescribed IVFs. Median duration of stay was five days; median cost of prescription and cost of IDs/IVFs in NRs
(US\$) were 648.5 (\$8.26) and 402 (\$5.12). IDs/IVFs constituted around $81.37 \%$ of the total drug cost. No significant gender variation in administration of IDs/IVFs was observed, but significant interdepartmental variation was observed (Table 4).

Significant differences in the median duration of stay were found between Medicine and OBG $(p=0.006)$ and Medicine and Pediatrics $(p<0.001)$ with higher duration of stay in Medicine. The mean number of drugs prescribed in Pediatrics was significantly $(p<0.001)$ lower than in Medicine, OBG and Surgery.

IDs/IVFs constituted $40.71 \%$ of the total drugs prescribed and $72.58 \%$ of the drug cost in Medicine. In Surgery $63.37 \%$ of the total drugs prescribed and $74.64 \%$ total cost of drugs was due to IDs/IVFs. In Pediatrics and Surgery, $56.71 \%$ and $66.78 \%$ of total prescribed drugs and $87.26 \%$ and $88.78 \%$ of the total cost of drugs were due to IDs/IVFs

The mean number of IAMs prescribed in Medicine, OBG, Pediatrics and Surgery were 0.71, 1.72, 1.09 and 1.69 , respectively. In Pediatrics, Medicine and Surgery, 51,48 and $44 \%$ of patients, respectively received at least one IAM. Table 4 compares frequency of IAM use in the four major departments. Types of antimicrobials prescribed in the four departments were similar except that coamoxiclav (Amoxicillin-Clavulanic acid fixed dose combination (FDC)) prescription was significantly higher in Medicine than in the other three departments. Ciprofloxacin (32\%) and a combination of three antimicrobials (Beta lactams, Gentamicin and Metronidazole) (44\%) was prescribed more in OBG compared to the other three departments.

Median number of IVFs prescribed in Medicine, OBG, Pediatrics and Surgery were one, one, one and two respectively. Table 4 compares frequency of prescription of various IVFs in the four departments.

Dextrose normal saline (DNS) was the most frequently administered IVF in the department of Medicine. In Surgery, Ringer lactate (RL) was most frequently administered. But RL and Isolyte $\mathrm{P}$ were the most frequently administered IVF in the department of OBG and Pediatrics, respectively.

\section{DISCUSSION}

In this study, a total of 938 (82.94\%) of the 1131 inpatients, discharged during the study period, received at least one injection during their hospital stay. This result is comparable to that reported from Eastern Nepal (7), where $77.7 \%$ of total inpatients had received IDs (note: IVFs were not included). In another study from Ghana, $60 \%$ of the patients received one or more injectable drugs (8). This may indicate higher rate of injectable administration in MTH. This maybe a matter of concern and the reasons for this should be 
investigated in detail.

The local patients frequently visit MTH for their illness, so the patients receiving injections [597 (63.65\%)] were mostly from Kaski district. District wise distribution of patients visiting MTH is similar to that noted in previous studies $(6,9)$ done at MTH. Nepal being a mountainous country, problems of accessibility to health care services is an important issue.

The median duration of hospitalization was five days. In a previous study (10) at MTH, median duration of stay was higher than that reported in the present study (nine days). On comparison between departments, mean duration of stay was highest in Medicine followed by Surgery. In a previous study (6) in the ICU of MTH, the mean \pm SD duration of hospitalization was $3.84 \pm 3.14$ days, which is lower than that reported from the medicine ward $(7.89 \pm 6.34)$ in the present study. Once a patient's condition improves, they are shifted to other wards and this may be the reason for shorter ICU stay. The patients are generally unwilling to stay in the hospital after IDs have been stopped (11, Personal observation of the authors and other healthcare providers). Economic considerations may be partially responsible for the desire to continue further treatment at home (11). Decreased use of IDs/IVFs will decrease the duration of stay and the costs associated. As stated previously (11) early switchover to oral preparations should be considered. Formulation of standard treatment guidelines and an antibiotic use policy in our

\begin{tabular}{|c|c|c|c|c|}
\hline $\begin{array}{c}\text { Name of } \\
\text { Injection }\end{array}$ & ATC Code4 & Frequency & $\begin{array}{c}\text { \% of } \\
\text { patients } \\
\text { prescribed } \\
\text { (N=938) }\end{array}$ & $\begin{array}{c}\text { DDD/ 100 } \\
\text { bed- } \\
\text { days }\end{array}$ \\
\hline Diclofenac & M01A B05 & 228 & 24.31 & 19.3 \\
\hline Ranitidine & A02B A02 & 212 & 22.6 & 15.65 \\
\hline Metronidazole & J01X D01 & 169 & 18.02 & 7.68 \\
\hline Gentamicin & JO1G B03 & 159 & 16.95 & 3.53 \\
\hline Ampicillin & J01C A01 & 147 & 15.67 & 5.22 \\
\hline Cefotaxime & J01D A10 & 147 & 15.67 & 2.41 \\
\hline Metoclopramide & A03F A01 & 128 & 13.65 & 3.65 \\
\hline Promethazine & R06A D02 & 115 & 12.26 & 6.86 \\
\hline Tramadol & N02A X02 & 106 & 11.3 & 2.11 \\
\hline Pethidine & N02A B02 & 102 & 10.87 & 0.58 \\
\hline
\end{tabular}

Table 1: ATC codes and DDD/100 bed-days of the ten most commonly used injectable drugs (IDs) in the study hospital is in progress.

The mean number of drugs administered was 8.75 . In a study from eastern Nepal (7), mean number of drugs was 5.3 and this figure would have been higher if IVFs were counted as drugs. A study by Shankar PR et al (10) in MTH reported the mean number of drugs to be 7.41, which is less than this study. Another study in Ghana (8) showed an average of 3.6 drugs prescribed per patient. Increased administration of IVFs may be a factor partly responsible for the increase in the mean number of drugs. The average number of drugs should be kept as low as possible to minimize the risk of drug interactions, development of bacterial resistance and hospital cost (12).

The average number of drugs was significantly higher in OBG (10.6) compared to the other three departments. Normal delivery and Lower Segment Cesarean Section were the most frequent clinical conditions for the admission to the OBG ward. In these conditions, multiple drug prescribing was common. Prescribing of more than one antimicrobial is also more frequent in OBG. In Medicine, the mean number of drugs was 9.56 which is less than that reported from Tribhuvan University Teaching Hospital (13) but higher than that reported from Harare (14). Elderly patients and patients

\begin{tabular}{|c|c|c|c|c|}
\hline $\begin{array}{c}\text { Name of Anti- } \\
\text { microbial }\end{array}$ & ATC Code 4 & Frequency & $\begin{array}{c}\% \text { of } \\
\text { patients } \\
\text { prescribed } \\
(\mathrm{N}=535)\end{array}$ & $\begin{array}{l}\text { DDD/ } 100 \\
\text { bed -days }\end{array}$ \\
\hline Metronidazole & J01X D01 & 169 & 31.59 & 7.68 \\
\hline Gentamicin & JO1G B03 & 159 & 29.72 & 3.53 \\
\hline Ampicillin & J01C A01 & 147 & 27.48 & 5.22 \\
\hline Cefotaxime & J01D A10 & 147 & 27.48 & 2.41 \\
\hline Ceftriaxone & J01D A13 & 75 & 14.02 & 3.66 \\
\hline Ciprofloxacin* & J01M A02 & 71 & 13.27 & $\begin{array}{c}3.77 \\
(2.41 \mathrm{O} \\
1.36 \mathrm{P})\end{array}$ \\
\hline Cloxacillin & J01C F02 & 64 & 11.96 & 3.15 \\
\hline Coamoxiclav & J01C R02 & 47 & 8.79 & 7.26 \\
\hline Amikacin & J01G B06 & 43 & 8.04 & 1.25 \\
\hline Cefazolin & J01D A04 & 33 & 6.17 & 0.35 \\
\hline
\end{tabular}

Table 2: ATC codes and DDD/ 100 bed-days of the ten most commonly used injectable anti-microbials (IAMs) in the study. * A single patient may have been prescribed more than one injectable preparation. 
with multiple conditions comprised the majority of patients being treated in the Medicine wards. This might be the reason for the greater average number of drugs in Medicine. In this study, it has been found that significantly lower number of drugs were used in Pediatrics (5.43) compared to other departments. Even though mean number of drugs prescribed in Pediatrics was less, the value is higher than the mean of 3.45 reported in a previous Zimbabwean study (15). But the result is comparable to the previous studies $(9,16)$ done in Nepal.

Of the total drugs prescribed, $53.98 \%$ were IDs/IVFs. This is very similar to that observed in a previous study (6) in MTH but higher than that reported from a study from eastern Nepal (7). In the present study, 17.91\% patients were administered a single injection, while $15.46 \%$ were administered two injections. The average number of injectable drugs should be kept as low as possible, to reduce poly-pharmacy, cost and hazards associated with the practice of injectables $(17,18)$. Mean number of injections administered was lowest in Pediatrics followed by Medicine. But mean number of IDs used is higher than that observed previously (1.68) (16). The percentage of patients receiving IVFs was

\begin{tabular}{|c|c|c|c|c|}
\hline $\begin{array}{c}\text { Type of } \\
\text { IVF }\end{array}$ & Frequency & $\begin{array}{c}\text { \% of Total } \\
\text { IVFs } \\
\text { (N=1328) }\end{array}$ & $\begin{array}{c}\text { \% } \\
\text { patient } \\
\text { receiving } \\
\text { injection } \\
\text { (N=938) }\end{array}$ & $\begin{array}{c}\text { Liters/ 100 } \\
\text { bed-days }\end{array}$ \\
\hline $\begin{array}{c}\text { Dextrose } \\
\text { Normal } \\
\text { Saline } \\
\text { (DNS) }\end{array}$ & 387 & 29.14 & 41.26 & 8.56 \\
\hline $\begin{array}{c}\text { Ringer } \\
\text { Lactate } \\
\text { (RL) }\end{array}$ & 330 & 24.85 & 35.18 & 5.77 \\
\hline $\begin{array}{c}\text { Normal } \\
\text { Saline (NS) }\end{array}$ & 260 & 19.58 & 27.72 & 5.3 \\
\hline $\begin{array}{c}5 \% \\
\text { Dextrose }\end{array}$ & 132 & 9.94 & 14.07 & 2.29 \\
\hline $\begin{array}{c}\text { Isolyte P } \\
\text { 10\% }\end{array}$ & 85 & 6.4 & 9.06 & 1.27 \\
\hline Dextrose & 76 & 5.72 & 8.1 & 0.82 \\
\hline $\begin{array}{c}\text { Total } \\
\text { Mannitol }\end{array}$ & $1328 *$ & 100 & & \\
\hline & 24 & 1.81 & 2.56 & 0.12 \\
\hline Others & 34 & 2.56 & 3.62 & 0.12 \\
\hline & & & & \\
\hline
\end{tabular}

Table 3: Utilization of Intravenous Fluids (IVFs)
$69.96 \%$ in Medicine (lower than that reported earlier) (13). Among the four departments, OBG administered IVFs to highest percentage of patients $(82.65 \%)$. The median number of IVFs used was higher in Surgery [2] compared to the other three departments. This is less than the median number of IVF prescribed [3] in a study from Spain (19). The utilization of IVF was $24.25 \mathrm{~L} / 100$ bed-days which is similar to the utilization in the ICU (6). Although DNS was the most commonly prescribed IVF in the MTH and in Medicine department, RL was the most frequently administered IVF in surgery and OBG. In OBG, RL was used as a vehicle to administer Oxytocin. This is different from that reported in other studies $(20,21)$. The first study (20) was carried out among post-operative surgical patients while the second studied various fluid maintenance therapy regimens in adult inpatients admitted to the general surgery ward over a one-year period. In a hospital in Serbia, Europe utilization of IVFs varied from 89 to $94 \mathrm{DDD} / 100$ beddays (22). Further studies on IVF utilization are required in MTH. An old study had looked at use of IVF among medical inpatients in hospitals in the United States, Scotland, New Zealand, Israel and Canada (23). Wide variations in the use of IVFs were noted. The use was maximum in US and least in Scotland and Israel. The percentage was $53.7 \%$ in the hospital with highest use. The present study shows a use ofa round $70 \%$. The study (23) was published in 1977 and the passage of time makes it difficult to draw conclusions.

Median cost of drugs and IDs/IVFs per patient was 8.26US\$ and 5.12US\$. However, the cost was higher than the mean cost of drugs observed previously (9) among pediatric inpatients who are less likely to suffer from multiple diseases. The cost of the prescription (and treatment) is an important variable in determining accessibility and concordance to treatment especially in Nepal where the per capita income is 260US\$ per year (24). MTH is a private sector health care provider where most of the patients have to pay for their treatment and medicines. But, to make the treatment accessible to patients belonging to low socioeconomic groups, the Poor Patient Fund (PPF) has been created and MTH organizes free treatment service 'camps' outside the hospital. These are health check up programs conducted by the hospital in outside locations. These could either be within Pokhara city, within the valley or outside

IAMs were prescribed in $57 \%$ of the patients. In a study from western Nepal (12), 51\% of the patients were prescribed injectable antibiotics. In an Indian study (25), 42.5\% of patients were prescribed antibiotics parenterally. Similarly, in an Israeli study (26), 64\% of patients were prescribed antibiotics parenterally. Apart from the cost associated with the injection procedure, IAMs are themselves costly. Early 
switch over from IAMs to oral antimicrobials can decrease the financial burden. An implementation program promoting early switch over from intravenous to oral quinolones ensured a total hospital saving of 41420US\$ during the time period considered (27). Similar programs could be implemented in MTH for cost effective use of IDs/IVFs.

Ampicillin and Cloxacillin FDC was defined to be irrational by the Drug and Therapeutics Committee of MTH and was not available in the MTH pharmacy. But, still a few prescriptions contained FDC. Coamoxiclav was the most commonly prescribed injectable FDC anti-microbial. Furthermore, it was found that a combination of three anti-microbials (betalactam, aminoglycoside and metronidazole) was often prescribed to patients. Educational interventions to reduce the prescription of coamoxiclav are underway and managerial interventions are being planned. The process of framing a hospital formulary is also in progress.

Departmental comparison showed the average number of IAMs prescribed was highest in OBG followed by Surgery, Pediatrics and Medicine. The lower mean does not signify that prescription of antimicrobials is lowest in Medicine because anti- microbials might have been used orally. Generally, prophylactic antibiotics were given parenterally in OBG and Surgery and that might be one of the reasons for the higher mean number of IAMs in these departments.

To prevent injection-associated infections, injection use needs to decrease and injection safety must be achieved (28). Several interventions were conducted world wide to decrease injection overuse and/or to achieve safer practice $(28,29)$. Some of them were very successful. Better communication between prescriber and patients and managerial approaches (i.e. restricting access to selected unnecessary and dangerous injectable drugs) can reduce overuse (28). The authors of a study conducted among private sector injection providers (pharmacies/medical shops and other venues) in the central region of Nepal (30) found unnecessary and unsafe use of injections to be common. Adverse effects like abscesses were common, unsafe handling and disposal of injection equipment and sharps is common and reuse of non-sterile injection equipment with the same patient was commonly observed. Providers failed to wash their hands or take other precautions while injecting and recycling waste was a problem (30). Certain of the problems mentioned may also be applicable to the hospital setting.

\begin{tabular}{|c|c|c|c|c|}
\hline \multirow[t]{2}{*}{ Parameters } & \multicolumn{4}{|c|}{ Department } \\
\hline & Medicine & OBG & Pediatrics & Surgery \\
\hline Duration (days) & $7.89 \quad(6.34)$ & $5.57 \quad(4.43)$ & $5.53 \quad(3.82)$ & $6.65 \quad(6.04)$ \\
\hline Number of drugs & $9.56 \quad(5.13)$ & $10.60 \quad(4.72)$ & $5.43 \quad(3.77)$ & $9.86 \quad(5.64)$ \\
\hline Number of injections & $3.89 \quad(3.08)$ & $7.14 \quad(4.21)$ & $3.08 \quad(2.78)$ & $6.58 \quad(3.94)$ \\
\hline & \multicolumn{4}{|c|}{ Frequency (percentage of total prescriptions for IAMs in the particular department) } \\
\hline & $(\mathrm{N}=104)$ & $(\mathrm{N}=72)$ & $(\mathrm{N}=103)$ & $(\mathrm{N}=154)$ \\
\hline \multicolumn{5}{|l|}{ No. of IAMs } \\
\hline 1 & $50(48.08)$ & $18(25.00)$ & $53(51.46)$ & $67(43.51)$ \\
\hline 2 & $37(35.58)$ & $20(27.78)$ & $31(30.10)$ & $44(28.57)$ \\
\hline$\geq 3$ & $17(16.34)$ & $34(47.22)$ & $19(18.44)$ & $43(27.92)$ \\
\hline & \multicolumn{4}{|c|}{ Frequency (percentage of total prescriptions for IVFs in the particular department) } \\
\hline & $(\mathrm{N}=184)$ & $(\mathrm{N}=81)$ & $(\mathrm{N}=\mathbf{8 9})$ & $(\mathrm{N}=163)$ \\
\hline \multicolumn{5}{|l|}{ Intravenous fluids } \\
\hline $\begin{array}{l}\text { Dextrose Normal Saline } \\
\text { (DNS) }\end{array}$ & $122(66.3)$ & $38(46.91)$ & $4(4.49)$ & $114(69.94)$ \\
\hline Ringer Lactate (RL) & $27(14.67)$ & $76(93.83)$ & $12(13.48)$ & $136(83.44)$ \\
\hline Normal Saline (NS) & $101(54.89)$ & $12(14.81)$ & $6(6.74)$ & $93(57.06)$ \\
\hline $5 \%$ Dextrose & $20(10.87)$ & $37(45.68)$ & $0(0)$ & $42(25.77)$ \\
\hline $10 \%$ Dextrose & $15(8.15)$ & $1(1.23)$ & $52(58.43)$ & $7(4.29)$ \\
\hline Isolyte P & $0(0)$ & $0(0)$ & $67(75.28)$ & $8(4.91)$ \\
\hline Others & 21(11.47) & $1(1.23)$ & $2(2.25)$ & $19(11.66)$ \\
\hline
\end{tabular}

Table 4: Comparison of various parameters, frequency of injectable antimicrobial (IAM) use and use of intravenous fluids (IVFs) among four major departments of MTH 
In the West, the need for parenteral therapy is an indication for hospitalization. Patients managed with other agents are treated as outpatients saving money for the healthcare system. In Nepal, patient demand for injections, and the inappropriate use of injections are a common health problem (31). Parenteral therapy is often started and maintained for the satisfaction of the patient, because of the patients' expectations of quicker recovery and for satisfying patient demand (Personal observation of the authors). So the issue of parenteral drug treatment in Nepalese hospitals should be studied in more detail.

Our study had many limitations. The study describes the pattern of injectable utilization, but did not investigate the reasons why. The study was carried out over a six month period (during the winter and summer months) and seasonal variations in disease pattern and drug utilization were not considered. A study of one year duration can offset the effect of seasonal variations. Drugs used for induction and maintenance of anesthesia, which are generally more expensive than drugs for many other uses, were also not considered but this was due to lack of proper documentation. Only the drug costs were considered and other costs were not taken into consideration. We did not look for the frequency of needle stick injuries among health workers. Follow-up of the patients and their opinion regarding the injectable use was not done and the rationality of drug use in different conditions was not assessed.

\section{CONCLUSION:}

The study provides an overview about utilization of IDs/IVFs among inpatients in MTH and could serve as a basis for further research, which will help prescribers to improve patient management by rationalizing injection practices. The high rate of prescription of IDs/IVFs is a matter of concern. Decreasing the prescription and early switch over to oral preparations will significantly reduce both the drug and non-drug cost (cost of injection, surgical items and hospital \& nursing charges). Guidelines for the prescription of injectable drugs (including IAMs) are required.

\section{ACKNOWLEDGEMENTS}

We acknowledge the help of Mr. Resham Thapa of the Medical Record Department (MRD), MTH and other staff of the department in carrying out the study. The help of Mr. Arjun Shrestha and his team of the Central Library, MCOMS, in searching relevant literature for the study is also gratefully acknowledged.

\section{REFERENCES}

1. World Health Organization. Introduction to Drug Utilization Research. Oslo: World Health Organization; 2003.
2. Hutin YJF, Hauri AM, Armstrong GL. Use of injections in health care settings worldwide, 2000: Literature review and regional estimates. BMJ. 2003; 327: 1075-1079.

3. World Health organization (WHO). Guiding principles to ensure injectable device security. Safe Injection Global Network (SIGN) Secretariat, Department of essential Health Technology; WHO: 2003. www.who.int/injection_safety/WHOGuidPrinciplesInjEquipFin al.pdf. Accessed on January 23rd, 2009.

4. World Health Organization Collaborating Center for Drug Statistics Methodology. Guidelines for ATC classification and DDD assignment 5th ed. Oslo: World Health Organization; 2001.

5. World Health Organization Collaborating Center for Drug Statistics Methodology. ATC index with DDDs 2009. Oslo: World Health Organization; 2008.

6. Shankar PR, Partha P, Dubey AK, Mishra P, Deshpande VY. Intensive Care Unit Drug Utilization in a Teaching Hospital in Nepal. Kathmandu Univ Med J. 2005; 3; 130-137.

7. Rehana HS, Nagarani MA, Rehan M. A study on the drug prescribing pattern and use of antimicrobials at a tertiary care teaching hospital in eastern Nepal. Indian J Pharmacol. 1998; 30:175-180.

8. Bosu WK, Ofori-Adjei D. A 1 day survey of drug prescribing patterns in the District General Hospital of the Wassa West District of Ghana. Trop Doct. 1997; 27: 222-226.

9. Shankar PR, Upadhyay DK, Subish P, Dubey AK, Mishra P. Prescribing pattern among paediatric inpatients in a teaching hospital in western Nepal. Singapore Med J. 2006; 47: 261-265.

10. Shankar PR, Subish P, Upadhyay DK, Dubey AK, Deshpande VY. Cephalosporin utilization in the in-patient wards of a teaching hospital in western Nepal. Pharmacoepidemiol Drug Saf. 2005; 14: 507-508.

11. Shankar PR, Partha P, Shenoy N, Joshy ME, Brahmadathan KN. Prescribing patterns of antibiotics and sensitivity pattern of common microorganisms in the internal medicine ward of teaching hospital in western Nepal: a prospective study. Ann Clinical Microbiol Antimicrob 2003; 2:7.

12. Stratton CW 4th, Ratner H, Johnston PE, Schaffner W. Focused microbiological surveillance by specific hospital unit: practical application and clinical utility. Clin Ther. 1993; 15 suppl A: 1220.

13. Joshi MP, Sugimoto T, Santoso B. Geriatric prescribing in the medical wards of a teaching hospital Nepal. Pharmacoepidemiol Drug Saf. 1997; 6: 417-421.

14. Nhachi CF, Zvaraya P, Kasilo J. Drug utilization in the geriatric population in the nursing homes and central hospitals of urban Harare. Cent Afr J Med. 1994; 40:126-131.

15. Nhachi CF, Kasilo OM, Nathoos S. Drug prescribing in paediatric in-patients at Harare and Parirenyatwa Central Hospitals. Cent Afr J Med. 1992; 38: 57-62.

16. Rauniar GP, Rani MAN, Das BP, Singh R. Prescribing pattern of antimicrobial agents in Pediatric inpatients. J Nepalgunj Med Coll. 2003; 3: 34-73.

17. Hersh BS, Popovici F, Jezek Z, et al. Risk factors for HIV infection among abandoned Romanian children. AIDS. 1993; 7 : 1617-1624.

18. Soeters R, Aus C. Hazards of injectable therapy. Trop Doct. 1989; 19: 124-126.

19. Navarro F, Martinez-Bengoechea MJ , Prieto M , Jaio N , Rodrogue Z-Sasiain JM. The extent of sodium ion and water administration associated with intravenous drug infusions in a surgical unit. J Clin Pharm Ther. 1994;19: 355-358.

20. Stoneham MD, Hill EL. Variability in post operative fluid and electrolyte prescription. Br J Clin Pract. 1997; 51: 82-84. 
21. Campo AM, Garcia RP, Martinez DC et al. Use of the maintenance fluid therapy in Surgery. Farm Hosp. 2004; 28: 8489.

22. Jankovic SM, Dejanovic SMD. Drug utilization trends in clinical hospital center "Kragujevac" from 1997 to 1999. Indian J Pharmacol. 2001; 33: 29-36.

23. Lawson DH. Intravenous fluids in medical in-patients. Br J Clin Pharmac. 1977; 4: 299-303.

24. The World Bank. Country Overview: Summary of economic development and World Bank assistance. http:// www.worldbank.org.np.

25. Gupta M, Malhotra S, Chandra KK, Sharma N, Pandhi P. Utilization of parenteral anti-infective agents in medical emergency unit of a tertiary care hospital: an observational study. Pharmacoepidemiol Drug Saf. 2004;13: 653-657.

26. Raven D, Levy Y, Schlesinger Y, Greenberg A, Rudensky B, Yinnon AM. Longitudinal surveillance of antibiotic use in hospital. QJM. 2001, 94: 141-152.

27. Pablos AI, Escobar I, Albinana S, Serrano O, Ferrari JM, Herreros de Tejada A. Evaluation of an antibiotic intravenous to oral sequential therapy program. Pharmacoepidemiol Drug Saf. 2005; 14: 53-59.
28. Hutin Y. Recent progress towards the safe and appropriate use of injections worldwide. WHO Essential Drug Monitor. 2005, 34: 6-7.

29. Zamin HT, Pitre MM, Conly JM. Development of an intravenous to oral route conversion program for antimicrobial therapy at a Canadian tertiary health care facility. Ann Pharmacother. 1997; 31: 564-570.

30. Bhattarai MD, Wittet S. Perceptions about injections and private sector injection practices in central Nepal. General Welfare Pratisthan and Gate's Children's Vaccine Program at PATH. December 2000. http://www.path.org/files/Nepal-InjectPractices-RA.pdf. Accessed on January 23, 2009.

31. INRUD, Nepal. 16th National Training Course on Rational Use of Drugs. INRUD Training Manual Series (Revised, English) 13. 